\title{
A Standardized, Evidence-Based Massage Therapy Program for Decentralized Elite Paracyclists: Creating the Model $^{\dagger}$
}

\author{
Ann Blair Kennedy LMT, DrPH(c), ${ }^{1 *}$ Jennifer L. Trilk PhD ${ }^{2}$ \\ ${ }^{1}$ Arnold School of Public Health/Department of Health Promotion, Education, and Behavior, University of South Carolina, \\ Columbia, SC, USA; ${ }^{2}$ University of South Carolina School of Medicine Greenville, Department of Biomedical Sciences, \\ Greenville, SC, USA
}

Background and Purpose: Evidence suggests that para-athletes are injured more often than able-bodied athletes. The benefits of massage therapy for these disabled athletes are yet to be explored. This paper documents the process followed for creating a massage program for elite paracycling athletes with the goal to assess effects on recovery, rest, performance, and quality of life both on and off the bike.

Setting: Massage therapists' private practices throughout the United States.

Participants: A United States paracycling team consisting of 9 elite athletes: 2 spinal cord injury, 2 lower limb amputation, 1 upper limb amputation, 1 transverse myelitis, 1 stroke, 1 traumatic brain injury, and 1 visually impaired.

Design: The process used to develop a massage therapy program for paracyclists included meetings with athletes, coaching staff, team exercise physiologist, and sports massage therapists; peerreviewed literature was also consulted to address specific health conditions of para-athletes.

Results: Team leadership and athletes identified needs for quicker recovery, better rest, and improved performance in elite paracyclists. This information was used to generate a conceptual model for massage protocols, and led to creation of the intake and exit questionnaires to assess patient health status and recovery. Forms also were created for a general health intake, therapist information, and a therapist's SOAAP notes.

Discussion: The conceptual model and questionnaires developed herein will help to operationalize an exploratory study investigating the feasibility of implementing a standardized massage therapy program for a decentralized elite paracycling team.

KEY WORDS: massage; athletics; disability; evidence-based; quality of life

\section{INTRODUCTION}

Interest in the Paralympic movement and sport has increased over the past decade, and in 2012 alone more than 4,000 athletes competed in the Paralympics in London. ${ }^{(1)}$ Individuals with health conditions, such as spinal cord injury, amputation, traumatic brain injury, and cerebral palsy who participate in sports, report improvements in physical health and quality of life (QOL) simply by being part of sport. ${ }^{(2,3)}$ Helping these athletes achieve stronger bodies, better rest, quicker recovery, and injury reduction/prevention may necessitate integrative strategies apart from standard training programs and care. The scientific evidence is robust for the physical and psychological benefits of massage therapy for able-bodied athletes. ${ }^{(4-8)}$ However, benefits of massage for disabled athletes are an area yet to be explored, in particular examining benefits related to their unique health conditions.

Fagher and Lexell ${ }^{(9)}$ indicate in their review of Paralympic sports that the research in athletic injury prevention is lacking. Studies report that para-athletes suffer from sports-related injuries (including overuse injuries) more often than able-bodied athletes. ${ }^{(9)} \mathrm{Up}$ per body soft tissue injuries appear to be the most prevalent. ${ }^{(10-12)}$ It has also been noted in the literature that there is great variability in reporting of injuries in the Paralympic games in the past and a need for longitudinal studies has been indicated. ${ }^{(1)}$ In able-bodied athletes, massage therapy can assist in rehabilitation of soft-tissue injuries ${ }^{(13-17)}$ and can improve psychosocial aspects such as depression, ${ }^{(18-20)}$ pain, ${ }^{(20-24)}$ and QOL, ${ }^{(25-28)}$ but none of these studies have focused on para-athletes.

This paper documents the processes taken to create a standardized massage program utilizing questionnaires and protocols guided by a conceptual model for elite paracycling athletes. With the understanding that massage therapy is an individualized treatment ${ }^{(29,30)}$

†Supplementary materials available at http://ijtmb.org 
from both the patient's and the massage therapist's point of view, we created protocols that would be patient-centered and individualized to the health condition and performance goals. This program was created with these specific athletes in mind with the hopes that other massage therapists in their treatment of para-athletes could use the products created (e.g., intake and exit questionnaires, protocols, and SOAAP note forms). Once the program is implemented, the overarching goal of the study is to investigate the feasibility of implementing a standardized massage therapy program using health condition-specific questionnaires for a decentralized elite paracycling team.

\section{METHODS}

The Roger C. Peace paracycling team at the Greenville Health System has 11 elite athletes of varying health conditions who are motivated to improve their athletic performance; however, only 9 of the team athletes will be participating in the massage program discussed herein. The athlete demographics can be seen in Table 1. To be included in the massage program, athletes must be a member of the team, sign an informed consent document approved by the Greenville Health System IRB, and maintain/ return communications from the research team. While the athletes have had the ability to pursue massage therapy on their own, the team sought to provide the service for the athletes as part of their athlete contract. The team leaders wish to incorporate regular massage therapy as a part of an integrative approach to their training protocol, and leadership want some guarantee that each athlete will be treated equally and with consistency. Other areas of concern are when the athletes travel to South Carolina for team camps and to team events. The team manager, who is also a massage therapist, treats the athletes at the camps and events as standard of care but has been without access to therapists' notes from the athlete's regular massage treatments. This has, at times, created gaps in care. Having access to regular treatment notes may help to improve treatments for the athletes when away from their regular therapist. With all of these issues in mind, it was decided that a massage program would be created with the goals of not only improving athletic performance but also of improving QOL. No standardized massage program exists to address these athletes' needs to enhance performance and prevent injuries.

The project began with a team meeting that included the coaching staff, team exercise physiologist, an athlete representative, and the first author, to inquire about their goals for the massage intervention, which was determined as assisting the athletes attain stronger bodies, better rest, quicker recovery time, and injury reduction/prevention. Field notes were taken during this meeting as a reference and source material for the project. A literature review was then conducted around the specific health conditions of the athletes, including spinal cord injury (SCI), traumatic brain injury (TBI), amputation, stroke, and blind/visually impaired, to investigate potential effects of massage on aspects of each health condition. Examination of secondary health concerns associated with these health conditions guided the creation of the questionnaires. For example, research indicates that massage therapy may ameliorate bowel dysfunction in those individuals with $\mathrm{SCI}^{(31)}$ and help with spasticity ${ }^{(32-35)}$ in individuals with SCI, TBI, and those who have had strokes.

The first author (MT1) and the team manager (MT2), two licensed massage therapists with a combined total of 38 years of professional massage experience, began exploring the concepts of assessment

TABle 1. Demographics of Athletes

\begin{tabular}{|c|c|}
\hline Gender & 8 Male 1 Female \\
\hline Age & $\begin{array}{c}\text { Mean: } 44.22 \\
\text { Median: } 47 \\
\text { Range: } 31-48\end{array}$ \\
\hline Race/Ethnicity & 9 Caucasian \\
\hline $\begin{array}{l}\text { Paracycling classification } \\
\text { Number of athlete(s) and classification }\end{array}$ & $\begin{array}{l}2 \mathrm{H} 3 \\
3 \mathrm{C} 5 \\
1 \mathrm{C} 4 \\
1 \mathrm{C} 2 \\
1 \mathrm{~T} 1 \\
1 \mathrm{BVI}\end{array}$ \\
\hline Health conditions & $\begin{array}{c}2 \text { Spinal cord injury } \\
2 \text { Lower limb amputation } \\
1 \text { Transverse Myelitis } \\
1 \text { Stroke } \\
1 \text { Traumatic Brain Injury } \\
1 \text { Upper limb amputation } \\
1 \text { Blind/Visually Impaired }\end{array}$ \\
\hline Years since injury & $\begin{array}{c}\text { Mean: } 21.33 \\
\text { Median: } 16 \\
\text { Range: } 2-48\end{array}$ \\
\hline $\begin{array}{l}\text { States of Athlete residence } \\
\text { Number of athlete(s) and state }\end{array}$ & $\begin{array}{c}3 \text { South Carolina } \\
2 \text { North Carolina } \\
1 \text { Oregon } \\
1 \text { Vermont } \\
1 \text { Florida } \\
1 \text { Florida/Ohio }\end{array}$ \\
\hline Prior massage experience & $\begin{array}{c}11 \mathrm{x} / \text { week } \\
12 \mathrm{x} / \text { month } \\
21 \mathrm{x} / \text { month } \\
21-2 \mathrm{x} / \text { year } \\
2 \text { not regularly } \\
1 \text { only } 1 \text { massage } \\
\text { previously }\end{array}$ \\
\hline Years competing & $\begin{array}{c}\text { Range: Less than } 2 \text { years } \\
\text { to } 20+\text { years }\end{array}$ \\
\hline
\end{tabular}

${ }^{a}$ One athlete splits his time between Florida and Ohio. 
and protocols of working with clients, and how these assessments can change the way therapists work with clients on the table and how this work might be adapted to para-athletes. Information about both therapists can be found in Table 2 .

Through an iterative process of working with the protocols, as well as intake forms, the two massage therapists had weekly meetings to discuss progress. While creating the protocols, the therapists discussed the driving force behind each protocol and why, how, and when the protocols should be utilized. For example, deep massage treatment is not recommended within two days of an event, as it may create undo inflammation and take one to two days to recover. ${ }^{(36)}$ Therefore, the general relaxation protocol would be used pre-race. The first author gathered a complete taxonomy and pressure descriptions from the relevant literature (Supplement 1: Taxonomies and Pressures) to describe and manualize the massage treatments, while allowing the protocols to be flexible and adaptive in design and application.

As part of the process, in the creation of the intake questionnaire, it was concluded a 10-point scale should be utilized when needed. In training, athletes gauge their training and effort based on a modified Borg ${ }^{(37)}$ 10-point perceived effort scale (Table 3). With this familiarity in mind, all rating scales (e.g., pain, sleep) were created in a similar format. The modified Ashworth scale ${ }^{(38)}$ measuring spasticity was also examined to inform the one health condition specific item surrounding spasticity in those with spinal cord injury, stroke, and traumatic brain injury. The questionnaire was reviewed by four experienced massage therapists in South Carolina (the team manager), Connecticut, Nevada, and Washington, to seek insight into ease of use and suggested changes.

Questionnaires were initially created using Google forms and then it was determined that, for more security, the REDCap system would be used to deliver the surveys as well as store the data. REDCap stands for Research Electronic Data Capture and is used for building and managing surveys and databases. (39) Surveys can be built and shared with ease through the REDCap system.

After the program is created, the subsequent step will be to identify and contact massage therapists in an athlete's hometown. If they express interest in working with the team and the athlete, the massage therapists will be trained via webcast in the protocols and methods for working with the athletes.

\section{RESULTS}

The conceptualized massage program with five distinct massage protocols can be seen in Figure 1. The goal of the program can be visualized in the center with the individual protocols as arms of the model. The five protocols are conceptualized as a general relaxation protocol, a muscle relaxation protocol, a combination general and muscle relaxation protocol, an injury rehabilitation protocol, and integrated injury rehabilitation, general and muscular relaxation protocol (dark gray boxes in Figure 1). The health condition specific intake form is used in assessment to determine which protocol should be used. In the model, the main drivers to the protocols are seen as gray gradient boxes; the white boxes are other influencers on what may sway the therapist to choose the protocol.

An examination of each protocol and the drivers to the protocol are needed to understand the flexibility of the program. The main driver to the general relaxation protocol is if the athlete has an $8+$ perceived exertion (PE) event with in the previous or within the next two days. This portion of the model was based on sports massage theory that deep work within two days of an event may cause undue soreness. $(7,36)$ With this in mind, the therapists are asked to not use pressures greater than a level 3 . The pressures are adapted from

TABLE 2. Massage Therapist Information

\begin{tabular}{|c|c|c|}
\hline Category & MT 1 & MT2 \\
\hline Highest level of education & Currently a DrPH candidate & Masters degree \\
\hline $\begin{array}{l}\text { Initial massage education hours and } \\
\text { school attended }\end{array}$ & $\begin{array}{c}500 \text { hours / SouthEastern School of } \\
\text { Neuromuscular and Massage Therapy - } \\
\text { Greenville campus }\end{array}$ & $\begin{array}{l}\text { Between 701-1000 hours } \\
\text { Boulder School of Massage Therapy }\end{array}$ \\
\hline First year working as an MT & 1999 & 1991 \\
\hline $\begin{array}{l}\text { Continuing education information: } \\
\text { Courses taken include but are not } \\
\text { limited to }\end{array}$ & $\begin{array}{l}\text { Neuromuscular therapy, craniosacral } \\
\text { therapy, myofascial release, pregnancy } \\
\text { massage, and sports massage }\end{array}$ & $\begin{array}{l}\text { Neuromuscular therapy, shiatsu, myofascial } \\
\text { release, and sports massage }\end{array}$ \\
\hline Provider of continuing education & $\begin{array}{l}\text { Courses provided include ethics and } \\
\text { research literacy }\end{array}$ & $\begin{array}{c}\text { Adjunct faculty and Mentor/intern } \\
\text { placement at Boulder School of } \\
\text { Massage Therapy }\end{array}$ \\
\hline
\end{tabular}


TABle 3. Rate of Perceived Effort (Exertion)

\begin{tabular}{lc}
\hline Level & Description \\
\hline 1 & Very very easy \\
2 & Very easy \\
3 & Easy \\
4 & Somewhat easy \\
5 & Not very easy \\
6 & Not very hard \\
7 & Somewhat hard \\
8 & Hard \\
9 & Very Hard \\
10 & Very very hard \\
\hline
\end{tabular}

Tracy Walton's work ${ }^{(40)}$ and descriptions of massage pressures can be seen on the SOAAP note form (Supplement 2: Project Forms) and in Supplement 1. The goal of this protocol is to prepare for or recover from a hard race or training session as well as if stress is indicated as high ( $\geq 6$ from the intake form), there is no pain, sleep issues are evident ( $\geq 8$ from the intake form), and/or they have muscle tension $\leq 5$. The strokes used should be slower and soothing in an effort to promote relaxation. The muscle relaxation protocol's main goal is to relieve muscle tension as indicated by $\mathrm{a} \geq 5$ on the intake form as the main driver to this protocol. There would also not be an $8+\mathrm{PE}$ in the previous or within the next two days. Other indications for this protocol would include decreased range of motion, pain $\leq 4$, spasticity $\geq 6$, and bowel issues. The pressures for this protocol call for

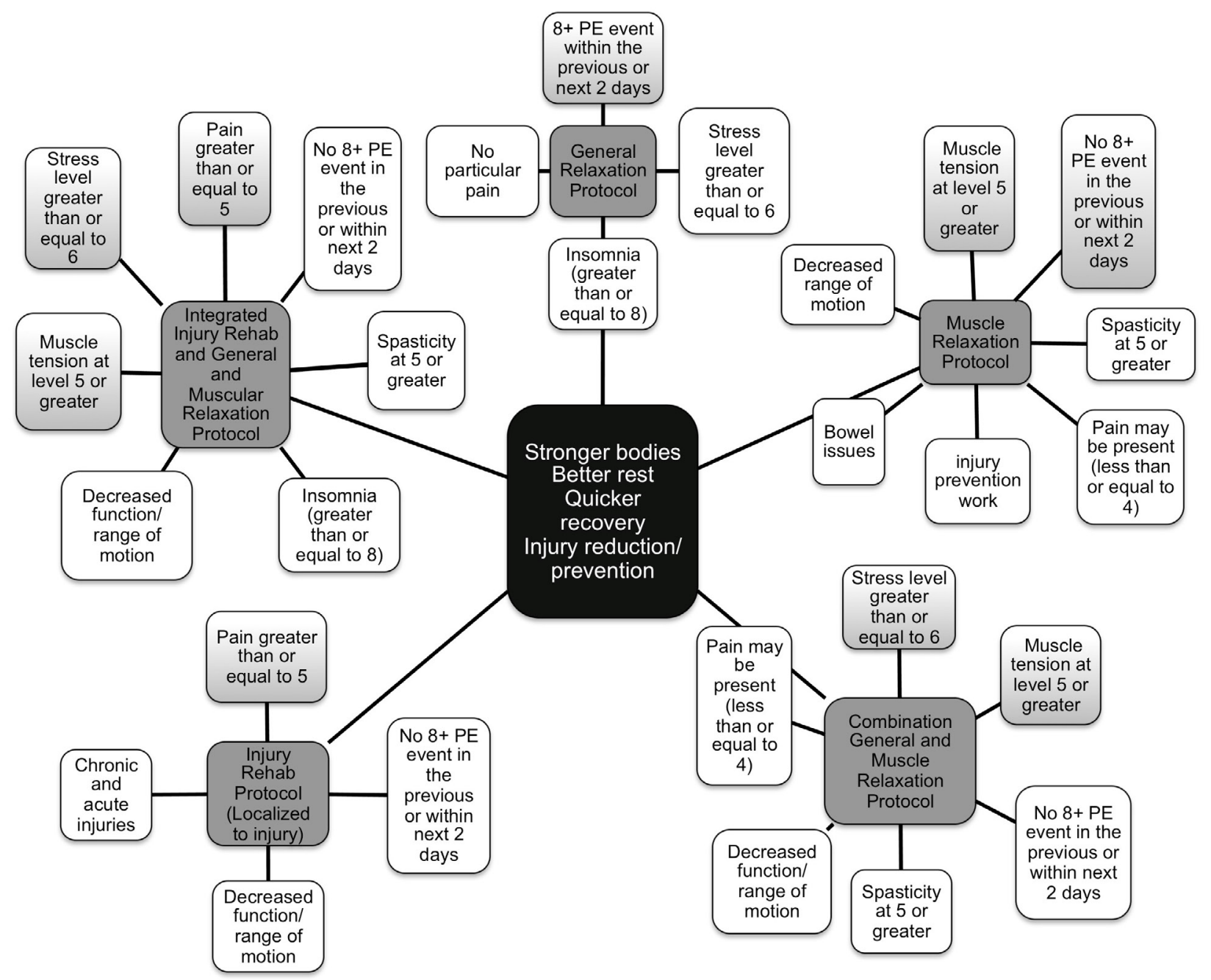

FIGURE 1. Conceptual model for protocols in a massage program for elite paracycling athletes. The purpose of the program is seen in the center (black box) with the massage protocols (grey boxes) seen in the 5 arms leading to the program purpose. The protocols are selected by information gathered from the intake form (Supplement 2). Main drivers to the protocols are seen in the gradient boxes. For example, in the Muscle Relaxation Protocol the main driver to the protocol is muscle tension $\geq 5$ and not having an $8+$ perceived exertion event within or in the previous two days. The white boxes indicate secondary considerations for using the protocol. 
3-5 generally. In the combination general relaxation and muscle relaxation protocol the main drivers are stress $(\geq 5)$ and muscle tension ( $\geq 5)$. Pain should be $\leq 4$, and spasticity if evident may be $\geq 6$; decreased function or range of motion may also indicate this protocol is needed. Therapists would use any range of pressures to help decrease stress and relieve muscular tension. The injury rehabilitation protocol is working on chronic or acute injuries and pain $\geq 5$. In this protocol the therapists is working with pressures between 1-5, depending on the injury and the athletes pain tolerance. The final protocol, Integrated Injury Rehab/Muscle Relaxation/General relaxation combination, combines all elements and is indicated by pain, stress, and muscular tension being $\geq 5$ for each of those indicators on the intake form. The purpose of this protocol is to help with injuries, as well as decrease stress and muscular tension.

With all the protocols, one specific item will allow the therapists to not use the protocol that may be indicated by the initial intake, this is the final question on the intake "What is your goal for today's session?" The reason this question supersedes the others can be seen in the following example. It is Thursday afternoon and the athlete is about to have their massage and they have an $8+$ perceived exertion race scheduled for Saturday morning. Generally, this would indicate that the therapists should only use the general relaxation protocol. However, the athlete's goal is to help relieve the intense "knot" in their hamstring so they will be able to race. The massage that may be used may require pressures greater than the level 3 indicated in the protocol and as this is the goal of the athlete to be able to race in less than two days. The adaptability of the program allows for such a veering away from the generally indicated protocol as long as the therapist documents in their SOAAP notes why a different protocol was used.

All the program specific forms can be seen in Supplement 2, highlighted portions of the intake and exit forms indicate branching logic used in the software. The branching logic was used for health condition-specific questions; for example, only those who marked their main health condition as "amputation" would receive the question about phantom limb pain and then the follow-up question about additional pain. Additionally, only those who mark spinal cord injury, stroke, traumatic brain injury, or cerebral palsy will be given the questions about spasticity. Finally, only those with spinal cord injury will receive the question about bowel issues, as this seems to be a particular difficulty for those with this condition. ${ }^{(31)}$

Based upon the intake questionnaire (Supplement 2: Project Forms), an exit questionnaire (Supplement 2) was created. This questionnaire will be emailed to the athletes the morning after their massage, and we have requested they complete the form no later than 24 hours after treatment to determine the effects of the therapy and to gauge the success of the treatment, with success being measured as meeting the athlete's goal(s) of the session.

After creating the intake and exit forms, the first author realized that more forms would be needed to complete the program. An initial health history of the athlete would be needed; this form was based on the Union Cycliste Internationale (UCI) health history form, with additional questions specifically regarding past massage therapy usage. The therapists would also need to complete SOAP notes; for uniformity, a form was created based on the included taxonomy and protocols. For this SOAP note form, an additional "A" was added to included Subjective, Objective, Assessment, Application, and Plan in the charting of the treatment. The final form that was created, which can be seen in Supplement 2, is a therapist information form. Once a therapist agrees to join the program, they are asked to fill out a short survey to inform the research team. Questions on this survey ask about years in practice, initial and continuing education hours, specific types of modalities practiced, main modalities practiced, as well as a brief description about their massage practice.

\section{DISCUSSION}

Currently the U.S. Olympic Committee, the U.S. Department of Defense, and the U.S. Department of Veteran Affairs are working to improve the lives of those wounded military veterans through involvement in sport. ${ }^{(41)}$ Investigation of the effects of massage therapy for this population is very important at this time with the increase of injured service men and women entering competitive sports through the above-mentioned partnerships. In addition, individuals with health conditions that were either acquired or congenital may be helped to achieve stronger bodies, better rest, quicker recovery, and injury reduction/ prevention through massage, which subsequently may necessitate integrative strategies apart from standard training programs and care.

The conceptual model and questionnaires will help operationalize an exploratory study to investigate the feasibility of implementing a standardized massage therapy program using health condition-specific questionnaires in a decentralized elite paracycling team. The treatment protocols will be used in training the massage therapists, creating flexible and adaptive therapy that is guided by a standardized intake form. This study also will measure the effectiveness of massage therapy, including a focus on domains surrounding pain and stress management, injury prevention and rehabilitation, improved sleep, function, and training capacity, along with management of the health condition. Information from this study will provide data to assist in integrative care for para-athletes.

Fagher \& Lexell ${ }^{(9)}$ indicate that little evidence for injury prevention in para-athletes exists. Innovative 
ways to prevent injury, improve rest, enhance recovery, and create stronger bodies for elite para-athletes are needed. The questionnaires and supplemental materials generated for this study may be used in massage therapy research and practice to assist in standardized assessment and in tracking progress of treatment for sport and nonsports participants with physical disabilities. Information from the pilot study utilizing this developed program will provide data to assist in integrative care for individuals with health conditions who compete in sport.

Additionally, massage therapists can make use of the created forms in Supplement 2 and adapt them for their specific patients/clients. These forms, specifically the intake and exit forms, could help massage therapists understand the impact of their treatment. Although the instruments have not yet been tested for their reliability and validity, ${ }^{(42)}$ they are simple and easy to use to assess client's goals and change from an individual session and over time. The feedback obtained may also help guide therapists in ways to better work with their chosen population.

\section{ACKNOWLEDGMENTS}

The authors would like to thank Jim Cunningham, Director Sportif of Team Roger C. Peace and Jerry Page, Manager of Team Roger C. Peace for their contributions and assistance with conceptualizing this program. No funding was used for this portion of the project; upon completion of the creation of the program, the American Massage Therapy Association began sponsoring Team Roger C. Peace and this sponsorship will fund the massage program's implementation, data collection, process evaluation, and data analysis. Also thanks to Jerry Page, LMT (SC), Lee Stang, LMT (CT), David Otto, LMT (NV), and Scott Lesieur, LMT (WA) for their review of the questionnaires.

\section{CONFLICT OF INTEREST NOTIFICATION}

No funding supported this portion of the project. Upon completion of the creation of the program, the American Massage Therapy Association began sponsoring Team Roger C. Peace and this sponsorship will fund the massage program's implementation, data collection, and data analysis. The first author reports activities related to acting as an expert witness, payment for lectures, and manuscript preparation. The second author reports no conflicts of interest.

\section{COPYRIGHT}

Published under the CreativeCommons AttributionNonCommercial-NoDerivs 3.0 License.

\section{REFERENCES}

1. Webborn N, Emery C. Descriptive epidemiology of Paralympic sports injuries. PM\&R. 2014;6(8 Suppl):S18-S22.

2. Yazicioglu K, Yavuz F, Goktepe AS, Tan AK. Influence of adapted sports on quality of life and life satisfaction in sport participants and non-sport participants with physical disabilities. Disabil Health J. 2012;5(4):249-253.

3. Blauwet C, Willick SE. The Paralympic movement: using sports to promote health, disability rights, and social integration for athletes with disabilities. $P M \& R$. 2012;4(11): $851-856$

4. Smith LL, Keating MN, Holbert D, Spratt DJ, McCammon MR, Smith SS, et al. The effects of athletic massage on delayed onset muscle soreness, creatine kinase, and neutrophil count: a preliminary report. J Orthop Sports Phys Ther. 1994;19(2):93-99.

5. Weerapong P, Hume PA, Kolt GS. The mechanisms of massage and effects on performance, muscle recovery and injury prevention. Sports Med. 2005;35(3):235-256.

6. Dawson KA, Dawson L, Thomas A, Tiidus PM. Effectiveness of regular proactive massage therapy for novice recreational runners. Phys Ther Sport. 2011;12(4):182-187.

7. Moraska A. Sports massage. A comprehensive review. J Sports Med Phys Fitness. 2005;45(3):370-380.

8. Brukner P, Khan K. Brukner \& Khan's Clinical Sports Medicine, 4th edition. New York: McGraw-Hill; 2012.

9. Fagher K, Lexell J. Sports-related injuries in athletes with disabilities. Scand J Med Sci Sports. 2014;24(5):e320-e331.

10. Patatoukas D, Farmakides A, Aggeli V, Fotaki S, Tsibidakis $\mathrm{H}$, Mavrogenis A, et al. Disability-related injuries in athletes with disabilities [Internet]. Folia Med. 2011;53(1). Retrieved 2014 Aug 12. Available from: http://www.degruyter.com/ view/j/folmed.2011.53.issue-1/v10153-010-0026-x/v10153010-0026-x.xml

11. Gawronski W, Sobiecka J, Malesza J. Fit and healthy Paralympians - medical care guidelines for disabled athletes: a study of the injuries and illnesses incurred by the Polish Paralympic team in Beijing 2008 and London 2012. Br J Sports Med. 2013;47(13):844-849.

12. Willick SE, Webborn N, Emery C, Blauwet CA, Pit-Grosheide $\mathrm{P}$, Stomphorst J, et al. The epidemiology of injuries at the London 2012 Paralympic Games. Br J Sports Med. 2013;47(7):426-432.

13. Van den Dolder PA, Roberts DL. A trial into the effectiveness of soft tissue massage in the treatment of shoulder pain. Aust J Physiother. 2003;49(3):183-188.

14. Khan KM, Brukner PD, Kearney C, Fuller PJ, Bradshaw CJ, Kiss ZS. Tarsal navicular stress fracture in athletes. Sports Med. 1994;17(1):65-76.

15. Elliott R, Burkett B. Massage therapy as an effective treatment for carpal tunnel syndrome. J Bodywork Mov Ther. 2013;17(3):332-338.

16. Best TM, Gharaibeh B, Huard J. Stem cells, angiogenesis and muscle healing: a potential role in massage therapies? $\mathrm{Br} J$ Sports Med. 2012;47(9).

17. Crane JD, Ogborn DI, Cupido C, Melov S, Hubbard A, Bourgeois JM, et al. Massage therapy attenuates inflammatory signaling after exercise-induced muscle damage. Sci Transl Med. 2012;4(119):119ra13. 
18. Brattberg G. Connective tissue massage in the treatment of fibromyalgia. Eur J Pain. 1999;3(3):235-244.

19. Moraska A, Chandler C. Changes in psychological parameters in patients with tension-type headache following massage therapy: a pilot study. J Man Manip Ther. 2009;17(2):86-94.

20. Moyer CA, Rounds J, Hannum JW. A meta-analysis of massage therapy research. Psychol Bull. 2004;130(1):3-18.

21. Cardenas DD, Jensen MP. Treatments for chronic pain in persons with spinal cord injury: a survey study. J Spinal Cord Med. 2006;29(2):109-117.

22. Frey Law LA, Evans S, Knudtson J, Nus S, Scholl K, Sluka KA. Massage reduces pain perception and hyperalgesia in experimental muscle pain: a randomized, controlled trial. $J$ Pain. 2008;9(8):714-721.

23. Kutner JS, Smith MC, Corbin L, Hemphill L, Benton K, Mellis BK, et al. Massage therapy versus simple touch to improve pain and mood in patients with advanced cancer: a randomized trial. Ann Intern Med. 2008;149(6):369-379.

24. Richards KC, Gibson R, Overton-McCoy AL. Effects of massage in acute and critical care. AACN Clin Issues. 2000;11(1):77-96.

25. Hamre HJ, Witt CM, Glockmann A, Ziegler R, Willich SN, Kiene H. Rhythmical massage therapy in chronic disease: a 4-year prospective cohort study. J Altern Complement Med. 2007;13(6):635-642.

26. Sturgeon M, Wetta-Hall R, Hart T, Good M, Dakhil S. Effects of therapeutic massage on the quality of life among patients with breast cancer during treatment. J Altern Complement Med. 2009;15(4):373-380.

27. Wilkie DJ, Kampbell J, Cutshall S, Halabisky H, Harmon H, Johnson LP, et al. Effects of massage on pain intensity, analgesics and quality of life in patients with cancer pain: a pilot study of a randomized clinical trial conducted within hospice care delivery. Hosp J. 2000;15(3):31-53.

28. Hillier SL, Louw Q, Morris L, Uwimana J, Statham S. Massage therapy for people with HIV/AIDS. Cochrane Database Syst Rev. 2010;(1):CD007502.

29. Ali A, Kahn J, Rosenberger L, Perlman AI. Development of a manualized protocol of massage therapy for clinical trials in osteoarthritis. Trials. 2012;13:185.

30. Schnyer RN, Allen JJB. Bridging the gap in complementary and alternative medicine research: manualization as a means of promoting standardization and flexibility of treatment in clinical trials of acupuncture. J Altern Complement Med. 2004;8(5):623-634.

31. Ayaş S, Leblebici B, Sözay S, Bayramoğlu M, Niron EA. The effect of abdominal massage on bowel function in patients with spinal cord injury. Am J Phys Med Rehabil. 2006;85(12):951-955.

32. Macgregor R, Campbell R, Gladden MH, Tennant N, Young D. Effects of massage on the mechanical behaviour of muscles in adolescents with spastic diplegia: a pilot study. Dev Med Child Neurol. 2007;49(3):187-191.

33. Whisler SL, Lang DM, Armstrong M, Vickers J, Qualls C, Feldman JS. Effects of myofascial release and other advanced myofascial therapies on children with cerebral palsy: six case reports. Explore. 2012;8(3):199-205.

34. Manella C, Backus D. Gait characteristics, range of motion, and spasticity changes in response to massage in a person with incomplete spinal cord injury: case report. Int J Ther Massage Bodywork. 2011;4(1):28-39.

35. Negahban H, Rezaie S, Goharpey S. Massage therapy and exercise therapy in patients with multiple sclerosis: a randomized controlled pilot study. Clin Rehabil. 2013;27(12):1126-1136.

36. Fritz S. Sports \& Exercise Massage : Comprehensive Care in Athletics, Fitness \& Rehabilitation. St. Louis, MO: Elsevier Mosby; 2005.

37. Borg G. Borg's Perceived exertion and pain scales. Champaign, IL: Human Kinetics; 1998.

38. Bohannon RW, Smith MB. Interrater reliability of a modified Ashworth scale of muscle spasticity. Phys Ther. 1987;67(2):206-207.

39. Harris PA, Taylor R, Thielke R, Payne J, Gonzalez N, Conde JG. Research electronic data capture (REDCap) - A metadatadriven methodology and workflow process for providing translational research informatics support. J Biomed Inform. 2009;42(2):377-381.

40. Walton T. Medical conditions and massage therapy: a decision tree approach. Philadelphia, PA: Wolters Kluwer/Lippincott Williams \& Wilkins Health; 2011.

41. Team USA. U.S. Paralympics: Military [Internet]. Retrieved 2015 Apr 11. Available from: http://www.teamusa.org/USParalympics/Military

42. DeVellis RF. Scale Development: Theory And Applications, $3^{\text {rd }}$ edition. Thousand Oaks, CA: SAGE; 2012.

Corresponding author: Ann Blair Kennedy, LMT, DrPH(c), Arnold School of Public Health, Department of Health Promotion, Education and Behavior, University of South Carolina, 915 Green S., Room 529, Columbia, SC 29208, USA

E-mail: kenneda5@email.sc.edu 